\title{
LA INFLUENCIA DE MICHEL FOUCAULT EN LOS MOVIMIENTOS DE LIBERACIÓN SEXUAL DURANTE LA TRANSICIÓN ESPAÑOLA
}

\section{MICHEL FOUCAULT'S INFLUENCE IN SEXUAL LIBERATION MOVEMENTS DURING THE SPANISH TRANSITION}

\author{
VALENTÍN GALVÁN \\ Universidad Pablo de Olavide (Sevilla)
}

Resumen: En el contexto de la Transición política española se produjo la eclosión definitiva de los movimientos de liberación sexual, vertebrados en torno a la «Coordinadora de Frentes de Liberación Homosexual del Estado Español» (COFLHEE). Este combate sexual, político y social, lo vinculamos con las investigaciones de Michel Foucault sobre las relaciones existentes entre el discurso sobre lo sexual, las prácticas de poder en la sexualidad, y las manifestaciones del placer surgidas —o reprimidastanto en el ámbito discursivo como en el ejercicio del sexo.

Palabras clave: Movimientos de liberación sexual, Michel Foucault, Transición política, España, La Voluntad de Saber.

АвSTRACT: In the context of the Spanish political transition, there was a definitive blossoming of sexual liberation movements, organized around the «Coordinator of the Spanish State's Fronts of Homosexual Liberation» (COFLHEE). We link this sexual, political and social combat to Michel Foucault's research on the relations that exist between speech about sexual things, the practices of power in sexuality, and the manifestations of pleasure that arise —or are suppressed — both in the discursive sphere and in the exercise of sex.

Keywords: Sexual liberation movements, Michel Foucault, Political Transition, Spain, La Volonté de Savoir. 


\section{Introducción: la complicidad represiva Iglesia-Estado durante el franquismo}

El artículo es una aportación a la recepción de Michel Foucault sobre el dispositivo de la sexualidad en Espańa. En éste se analizan diferentes grupos de liberación sexual y sus luchas políticas, destacando la lectura foucaultiana de un grupo de homosexuales militantes pertenecientes a la «izquierda revolucionaria».

A lo largo del franquismo la influencia del catolicismo fue preponderante en cuestiones de moralidad. La Iglesia impuso una ética social y sexual basada en el matrimonio indisoluble, monogámico y sexualmente vergonzante. La Dictadura y la Iglesia convirtieron deliberadamente a la familia en la columna vertebral del sistema y en un instrumento eficaz de control de sexualidad. Con estos antecedentes, en las familias de la posguerra se fomentó aún más el rechazo y el encierro de los homosexuales. Un policía, conocido como Mauricio Kart, publicó Sodomitas en 1956. En esta monografía — que alcanzó su décimo segunda edición en 1973 - alejada de cualquier rigor científico, podemos leer pasajes como éste:

La manada de fieras sodomitas, por millares, se lanza a través de la espesura de las calles ciudadanas en busca de su presa juvenil. Disfrazada de persona, la fiera sodomítica ojea entre el matorral ambulante de las aceras su pieza preferida, el cándido muchacho, más grato a su ávida pupila cuanto más inocencia lleva retratada en su fisonomía (...) Vuestro hijo puede volver a casa corrompido, guardando su bochornoso secreto, que nada delatará; la monstruosa relación continuará y, dada su edad, su instinto sexual se torcerá y será para siempre un invertido. (Carlavilla 1973,11-12).

Conviene diferenciar entre homosexualidad y paidofilia, a menudo intencionadamente confundidas por sectores interesados. La paidofilia abarca las relaciones sexuales entre un individuo adulto y un niño o niña, por tanto lo determinante de la relación no es el sexo sino la edad. Aún en 1967, se dictaban Sentencias del Tribunal Supremo, en las que el Juez utilizaba contra los actos homosexuales calificativos como: "contranatura, torpes, impropios de personas cultas, libidinosos, obscenos, impuidicos, repugnantes, inmorales, viciosos, de extravio sexual, lúbricos, ofensivos contra la moral media de los pueblos cultos, lascivos, que ponen al descubierto los bajos fondos sociales». (Mapelli, Grosso 1978,18-20, 20). 


\section{Los grupos de liberación homosexual y la Ley de Peligrosidad y Rehabilitación Social}

La aparición del primer grupo de liberación homosexual estuvo directamente relacionada con la promulgación de la Ley de Peligrosidad y Rehabilitación Social (LPRS) ${ }^{1}$ de 1970, durante el Gobierno de Carrero Blanco. En la Introducción se justifica la LPRS como:

un sistema de normas nuevas encaminadas a la aplicación de medidas de seguridad a los sujetos socialmente peligrosos e inspiradas en las orientaciones de la rama científica que desde hace años se conoce con el nombre de Defensa Social (...) Una situación de peligro subjetivo que ha de deducirse no sólo de las circunstancias objetivas descritas en cada una de las categorías de sujetos peligrosos, sino especialmente de la investigación antropológica, psíquica y patológica del sujeto.

El legislador, con la pretendida neutralidad y objetividad de la ciencia, se apoyaba en los supuestos científicos de la antropología, la psiquiatría y la psicología. Estas ciencias de la conducta - junto a la Iglesia y la familia — se convirtieron en depositarios de los valores establecidos por los grupos dominantes para justificar y perpetuar su dominio ${ }^{2}$.

Continuando con el análisis de la LPRS, refiere en su artículo 2. ${ }^{\circ}$ : «serán declarados en estado peligroso y se les aplicarán las correspondientes medidas de seguridad, quienes: (...) b) se aprecie en ellos una peligrosidad social. Son supuestos de estado peligroso los siguientes: (...) 3. ${ }^{\circ}$ Los que realicen actos de homosexualidad $»^{3}$.

Las medidas de seguridad se concretaron, según el artículo $6 .^{\circ}$, en «el internamiento en un establecimiento de reeducación que dotados del personal idóneo necesario garantizarán la reforma y rehabilitación social del peligroso y en la prohibición de residir en el lugar o territorio que se designe».

1 La Ley de Vagos y Maleantes, vigente desde 1933, se reformó en 1954 para incluir a los homosexuales en el marco de aplicación de la ley; posteriormente sustituida por la Ley de Peligrosidad y Rehabilitación Social. El Anteproyecto de la LPRS fue redactado por Antonio Sabater y Tomás. El célebre Juez Especial de Peligrosidad reveló en sus obras criterios subjetivos, discriminatorios y denigratorios hacia diferentes grupos marginados, en especial a los homosexuales y gitanos. (Sabater, 1962).

2 Gómez Beneyto, M. (1978). "Algunos aspectos médicos, psicológicos y jurídicos de la homosexualidad» en Torres González, F. (coord.), 1978, 141-154.

3 Citado por Llamas, R., Vila, F. (1977) en Buxán, X. M. (ed.), (1997, 193). 
Tan denigrante era el concepto de peligrosidad social como el de reintegración a través de la educación. Según la ley, a homosexuales y prostitutas, se les aplicaba la duración de la pena que podía oscilar entre seis meses y cinco años. A propuesta del director del centro podía llevarse a cabo un juicio de revisión antes de su prescripción, en el supuesto de que hubiesen cambiado las condiciones de peligrosidad del internado. Se crearon dos establecimientos de reeducación, uno en Huelva y otro en Badajoz, ambos para varones. En el caso de una mujer lesbiana la ley no preveía su destino, si bien es cierto que las denunciadas por su homosexualidad fueron muy escasas. A finales de 1975 un tribunal de Barcelona condenaba a un hombre, por declarar abiertamente su homosexualidad, con la pena de expulsión del territorio catalán y el internamiento en un centro penitenciario especial en Huesca. Como protesta, veinticuatro psiquiatras catalanes firmaron el denominado «Documento de los 24» con una única pretensión: que las autoridades y la sociedad machista espańola cambiase sus prejuicios sobre la homofobia ${ }^{4}$. Mientras que los partidos políticos y los movimientos de liberación de la mujer ${ }^{5}$, legales o no, podían realizar abiertamente sus campañas, los movimientos de homosexuales tenían que mantenerse en la clandestinidad, en tanto que las leyes vigentes prohibían toda organización que atentase contra la moral y las buenas costumbres. La homosexualidad se consideraba un ataque a los principios católicos y puritanos impuestos por el franquismo.

4 Para consultar el documento véase «Homosexualidad y Represión» en Soriano, M. (1978, 37-47). El grupo de liberación homosexual «Dignitat» publicó en su revista-boletín el «Documento de los 24», con fecha 11 de Enero de 1976.

5 En 1965 se celebra en Barcelona la 1. a Asamblea General en la que se constituyó el «Movimiento Democrático de Mujeres». A partir de 1971 surgieron nuevos grupos: la «Asociación de Mujeres Juristas» (1971) y la «Asociación Española de Mujeres Separadas» (1974). 1975 fue declarado por la ONU como "Año Internacional de la Mujer», contexto que propició las condiciones necesarias para la celebración en Madrid de las "Jornadas Nacionales por la Liberación de la Mujer", del 6 al 9 de Diciembre, a los pocos días de la muerte de Franco. Estas jornadas pueden considerarse el primer encuentro feminista de carácter nacional que se celebró en España, en la que se enfrentaron las dos posturas que polarizaban el debate feminista: el llamado «feminismo radical» y el «feminismo de la lucha de clases».

Asimismo, en mayo de 1976, se celebraron en Barcelona las «1. a Jornades Catalanes de la Dona» que marcaron no sólo el periodo de expansión del movimiento feminista en España, sino también una auténtica eclosión de organizaciones de mujeres, aunque muchas de ellas de carácter efímero. El tercer gran encuentro del feminismo español durante la transición tuvo lugar en Granada, en mayo del 1979, donde se celebraron las «II Jornadas Estatales de la Mujer». Al debate anterior sobre la militancia única o doble, se añadió en estas jornadas otro más novedoso: el del «feminismo de la igualdad» y el «feminismo de la diferencia». Véanse, Moreno Sardá, A. (2007); Folguera, P. (2007). 
A partir de la LPRS se inició la organización y labor del movimiento de liberación gay y de lesbianas. Desde Cataluña se extendió por todo el país: Valencia, Mallorca, Madrid, Málaga, Zaragoza, Santiago de Compostela, Bilbao, etc. En enero de 1972 la «Agrupación Homosexual para la Igualdad Sexual» publicó el Boletín clandestino mensual AGHOIS ${ }^{6}$, contracción del grupo, organización que pasó a denominarse «Movimiento Español de Liberación Homosexual». En AGHOIS se publicaron artículos sobre la problemática homosexual desde perspectivas tan distintas como la jurídico-legal, religioso-moral, médico-científica, socio-política, histórico-biográfica, etc. ${ }^{7}$

El «Movimiento español de liberación homosexual» (MELH) se constituyó con el objetivo de concienciar a los homosexuales en la reivindicación de sus derechos, y para conseguir su aceptación y reconocimiento por parte de la sociedad. A finales de 1975 sus integrantes reforzaron el perfil ideológico y el movimiento pasó a denominarse "Front d'Alliberament Gay de Catalunya" (FAGC) ${ }^{8}$. En el «1. ${ }^{\circ}$ Congreso Internacional de Marginación Social» de 1976, celebrado en Burjassot (Valencia), el FAGC mantuvo contactos con jóvenes estudiantes y trabajadores, constituyéndose el «Front d'Alliberament Homosexual del País Valencià» (FAHPV) y el «Front d'Alliberament Gay de les Illes» (FAGI) en Mallorca. A finales de 1976, se celebraron diferentes Asambleas Constituyentes - por lo que el FAGC dejó de ser un grupo reducido- aprobándose un «Manifiesto» que se dio a conocer a la prensa y a los partidos políticos, desde el centro izquierda a la izquierda más radical, con la intención de que tomasen una postura concreta respecto a la homosexualidad.

\section{EI «Manifiest» del Front d'Alliberament Gay de Catalunya}

El «Manifiest» del «Front d'Alliberament Gay de Catalunya» se considera el primer análisis político de la cuestión homosexual. Este texto, de Marzo de

${ }^{6}$ En diciembre de 1972, AGHOIS contaba con un centenar de suscriptores. Para evitar riesgos el boletín era multicopiado en París por el grupo "Arcadie», apareciendo desde el número 5 como «Suplemento de Arcadie para los amigos de España». El Boletín se publicó en Francia hasta 1974, aunque ya en 1973 López Rodó, Ministro de Asuntos Exteriores, presionó para que no se publicase en París.

7 Fluviá, A. (1977) en Weinberg, M., Williams, C. J. (eds.), (1977, 485-501).

8 Para más información sobre la génesis y desarrollo de los movimientos de liberación homosexual en España véase, De Fluviá, A. en Enríquez, J. E. et al., (1978,149-167); Haro Ibars, E. $(1978,59)$. 
1977, se utilizó de base para una definitiva elaboración de la teoría de la liberación sexual, sirviendo de plataforma orientativa para la gran mayoría de los movimientos gays en España. Las reivindicaciones fundamentales del FAGC fueron: la derogación de la Ley de Peligrosidad y Rehabilitación Social; amnistía para todos los encarcelados y recluidos por causa de una conducta homosexual; y la obligación de impartir una educación sexual adecuada en todos los niveles de enseñanza, sin hacer discriminaciones con la homosexualidad. El FAGC entendió la enseñanza sexual no sólo como medio de reproducción sino primordialmente como fuente de placer y de comunicación interpersonal.

La ideología del manifiesto parte de un análisis marxista de la sexualidad:

Creemos que la lucha por nuestras libertades está inmersa dentro de una lucha por la liberación sexual del individuo y ésta está dentro de la lucha por la liberación total del individuo humano, e inmersa en la lucha de clases. Nosotros no somos reformistas, somos radicales y revolucionarios. No nos contentamos con que cambien las leyes. Hay una serie de estructuras que oprimen a una serie de gente: la familia, la escuela, que tal como están establecidas por la clase dominante, es necesario cambiarlas?.

Entre sus filas el FAGC tenía afiliados y simpatizantes de partidos como Acción Catalana, Federación de Partidos Socialistas (FPS), Partido Socialista Popular (PSP), Partit Socialista Unificat de Catalunya (PSUC), Partido Comunista de Unificación (PCU), Movimiento Comunista (MC), Liga Comunista revolucionaria (LCR), Acción Comunista (AC), Confederación Nacional de Trabajadores (CNT), Organización de Izquierda Comunista de España (OICE), etc. ${ }^{10}$

El FAGC pretendió romper el aislamiento en que se encontraban los homosexuales, realizando una decisiva clarificación ideológica de la problemática sexual. La opresión sobre la mujer y los homosexuales partían básicamente de la misma ideología sexista y machista, por lo que sus mejores aliados fueron los movimientos de liberación de la mujer, en tanto que la práctica de la unidad de acción podía ser muy fructífera para favorecer la liberación sexual: «invita, pues, el FAGC, a todos los movimientos de mujeres y entre ellas a «Mujeres Libres» a

9 Viladegut, P., Solís, D. (1977, 34-35).

${ }^{10}$ Mesa Redonda (1977, 78-87). En el coloquio, «Homosexuales, una lucha marginal», intervinieron miembros del FAGC, Dignitat y una representación de homosexuales independientes. 
colaborar conjuntamente en nuestra lucha para acabar con las segregaciones de todo tipo y para conseguir la total liberación sexual» ${ }^{11}$.

Con posterioridad al "Manifiesto» se presentaron públicamente varios grupos de liberación homosexual. En Madrid, el «Frente Homosexual de Acción Revolucionaria» (FHAR), el «Movimiento Democrático de Homosexuales» (MHD) y la "Agrupación Mercurio para la Liberación Homosexual»; en Málaga, la «Unión Democrática de Homosexuales de Málaga» (UDHM) y en Bilbao, «Euskal Herriko Gay Askaten Mugimendua» (EHGAM). La mayoría tuvieron un destacado carácter radical y revolucionario por sus reivindicaciones sociales y políticas. Consciente de la convergencia de la lucha por la liberación de la mujer y los homosexuales, el FHAR — de ideología libre pues no estuvo adscrito a ningún partido político - se propuso colaborar estrechamente con el movimiento feminista. Por su parte, el objetivo primordial de la "Agrupación Mercurio» ${ }^{12}$ consistió en plantear la revolución sexual de la sociedad dentro del marco de una revolución social y cultural que rompiese con las estructuras opresoras, políticas, económicas y sobre todo ideológicas. Para esta organización, democrática y asamblearia en su funcionamiento interno y abierta a todas las ideologías, la liberación sexual en general y la homosexual en particular no podía ser orientada más que como una lucha política que asumiese la destrucción del orden socio-económico actual, y su sustitución por otro que permitiese la superación de la lucha de clases. A su vez, el «Movimiento Democrático de Homosexuales» (MDH) surgió ante la imperiosa necesidad de buscar alternativas democráticas a todos los niveles, declarándose abiertamente partidario de una sociedad democrática en vías del socialismo. Para el MDH, la sociedad de clases y las instituciones basadas en la defensa privada fueron históricamente la base de la tradicional represión e incesante condena y persecución de la homosexualidad.

En el mes de Marzo de 1977 se organizó, en la Facultad de Derecho de la Universidad de Madrid, la «1a Semana de Solidaridad con los Presos Comunes»" Estas jornadas coincidieron con otras convocadas por el FHAR, la «Semana de lucha contra la Ley de Peligrosidad y Rehabilitación Social», iniciativa a la que

11 Documento firmado por Helios en VV. AA. (1977, 231-233, 233).

12 La "Agrupación Mercurio» en un comunicado (julio de 1977) informó de su fusión con algunos miembros del FHAR y el MDH, constituyendo un nuevo grupo denominado «Frente de Liberación Homosexual de Castilla» (FHHOC).

13 Jornadas celebradas del 21 al 25 de marzo de 1977 en la Facultad de Derecho de la Universidad Complutense de Madrid, organizadas por la Asociación «Cultura y Derecho» que presidía F. J. Álvarez García. 
se sumó la "Coordinadora de Presos en Lucha» (COPEL) con un comunicado redactado desde la cárcel de Carabanchel ${ }^{14}$. Éstos fueron los inicios de la «Coordinadora por la abolición de la Ley de Peligrosidad y Rehabilitación Social» ${ }^{15}$, cuya invitación se hizo extensiva a fuerzas políticas y organizaciones de los sectores sociales marginados como presos comunes, homosexuales, feministas, psiquiatrizados, minusválidos, etc. El 21 de Mayo de 1977 en una rueda de presa, celebrada en el Club de Amigos de la UNESCO de Madrid, los diferentes grupos de liberación homosexual —Agrupación Mercurio, FAGC, FHAR, MDM, UDHM, EHGAM, FAGI, FAHPV, el «Movimiento Homosexual Aragonés» (MHA) y el «Movimiento de Liberación Homosexual de Granada» (MLH) firmaron un comunicado exigiendo la derogación de la LPRS y la disolución de los tribunales que aplicaban dicha ley. También mandaron una carta dirigida al Ministro de Justicia, en la que recordaban a Landelino Lavilla ${ }^{16}$ la reciente adhesión de España a la «Declaración Universal de los Derechos Humanos» ${ }^{17}$.

La mayoría de estos colectivos de homosexuales coincidieron en la necesidad de constituirse en una sola formación que los aglutinase o reagrupase, de ahí el nacimiento de la «Coordinadora de Frentes de Liberación Homosexual del Estado Español» (COFLHEE). Independientemente de los grupos mencionados, dedicados a la lucha política y reivindicativa, existieron otros de tipo humanístico y cristiano con un carácter reformista e integracionista. En Valencia, desde 1968, el sacerdote Antonio J. de Mora dirigió desde 1968 la «Fraternidad Cristiana de la Amistad ${ }^{18}$. Esta organización atendía a todos los marginales sociales, aunque

${ }^{14}$ Comité Pro-Presos de CNT, (1977, 36-39).

15 El primer comunicado de la «Coordinadora por la abolición de la Ley de Peligrosidad y Rehabilitación Social» se hizo público en Abril de 1977. En éste firmaron las siguientes organizaciones: Acción Comunista (AC), Comités de Apoyo a COPEL; Confederación Nacional del Trabajo (CNT), Frente Homosexual de Acción Revolucionaria (FHAR), Frente de Liberación de la Mujer (FLM), Juventudes Comunistas Revolucionarias (JCR), Juventudes Socialistas (JJ. SS.), Liga Comunista Revolucionaria (LCR), Mujeres Libres, Organización de Izquierda Comunista (OIC), Seminario Colectivo Feminista. Posteriormente se sumaron el «Colectivo de psiquiatrizados en lucha», el "Colectivo feminista», "Minusválidos unidos» $\mathrm{y}$ "Grupos de educación especial». Véase López Linage, J., (coord.), (1977, 26-27).

${ }^{16}$ El diario El País publicó una nota de prensa, el 22 de mayo de 1977, sobre la carta al Ministro de Justicia: «seis mil firmas promovidas por los grupos homosexuales. Se pide la derogación de la Ley de Peligrosidad Social. La carta, entre otras personas, la firmaron el Presidente de la Asociación de Derechos Humanos, Joaquín Ruiz-Giménez, Rafael Alberti, Pablo Castellano, Antonio Gala, Juan Antonio Bardem, Eloy de la Iglesia, Pedro Olea, etc.»

17 Soriano, M. (1978, 116).

${ }^{18}$ Este grupo organizó el Primer Congreso Internacional de Marginación Social, celebrado en Burjassot (Valencia) los días 1 y 2 de mayo de 1976. En este encuentro participaron, entre otros, 
dedicada preferentemente a la orientación de los homosexuales y lesbianas. Y en Barcelona el ex-jesuita Salvador Guash i Figueras fundó en 1976 el grupo «Dignitat»" ${ }^{19}$, a semejanza del movimiento norteamericano «Dignity», en el que sólo tenían cabida los católicos, con la particularidad para el caso español de ser un grupo pluralista que también admitió a ateos y agnósticos ${ }^{20}$. Por su parte, el FAGC fundó, con un carácter completamente laico, el «Institut Lambda» de Barcelona, ante la necesidad perentoria e inaplazable de dar una respuesta racional a la problemática que tenían la mayoría de los homosexuales. El «Institut Lambda» se constituyó como una empresa colectiva sin fines lucrativos, formada por personas de diferentes profesiones, dedicada a la asistencia, ayuda y orientación de los homosexuales.

El 26 de Junio de 1977 se celebró en Barcelona el primer «Día Mundial del Orgullo Gay». En el comunicado hecho público se explicaba el doble motivo de la convocatoria: por un lado se exigía la inmediata derogación de la discriminatoria Ley de Peligrosidad y Rehabilitación Social, y por supuesto se trataba de celebrar por primera vez en Espańa el «Día Mundial del Orgullo Gay», fecha en la que se conmemora el inicio de las movilizaciones homosexuales en el mundo. Los acontecimientos fueron lamentables, la manifestación fue brutalmente reprimida por la policía antidisturbios, siendo numerosos los agredidos y detenidos ${ }^{21}$. Con esta actitud el gobierno demostró el escaso espíritu democrático que todavía imperaba en nuestro país a mediados de 1977.

Con la aprobación de la Constitución española en Diciembre de 1978 se derogó la Ley de Peligrosidad y Rehabilitación Social, por ser incompatible con

el psiquiatra Manuel Gómez-Beneyto, el sociólogo José Vicente Marqués y el teólogo Enrique Miret.

${ }^{19}$ Los principios del grupo «Dignitat» se aprobaron por unanimidad en su Primera Asamblea, celebrada en Montserrat los días 16 y 17 de Octubre de 1976.

${ }^{20}$ Dentro de «Dignitat» existió un grupo de apoyo al homosexual deprimido para luchar contra sus propios prejuicios. Como consecuencia, se separó de Dignitat el grupo «Fénix de homosexuales», quienes trabajaron en un proyecto de integración para personas marginadas en la sociedad. También véase, "Aspectos reivindicativos del FAGC y del FHAR", (1977, 36-37).

${ }^{21}$ El 29 de Junio de 1977, el periódico catalán Mundo Diario publicaba en sus columnas: «En la pasada madrugada fue presentada una demanda en el Juzgado de Guardia por los presuntos malos tratos inferidos por la Policía a un detenido en la manifestación gay del pasado domingo en las Ramblas. La denuncia fue admitida a trámite por el juez, que, al parecer, habló con la denunciante y una testigo de la paliza inferida a Oriol Martí Casas, militante de OCE-BR (Organización Comunista de Espańa-Bandera Roja), médico y PNN de la Universidad Autónoma. Oriol Martí fue ingresado en la cárcel Modelo, y al parecer, se le ha abierto sumario por posible agresión a la fuerza armada por parte de la jurisdicción militar». 
la democracia, básicamente en lo referido al concepto de peligrosidad social y al de su rehabilitación. Estas contrariedades fueron subsanadas por vía de urgencia en Enero de 1979 con una reforma legal en la que se eliminaron varios artículos de la LPRS, entre ellos el referente a los actos de homosexualidad. Se trataba no sólo de cambiar y derogar leyes, sino también de que los gays y lesbianas españoles tomaran la palabra para cambiar estructuras y derribar prejuicios: «es preciso, pues, que nuestra voz se oiga para des-velar y re-velar los aspectos comunes de nuestra realidad como mujeres y reivindicar nuestra diferencia como lesbianas» ${ }^{22}$.

A la opresión soportada por la mujer durante el franquismo, como instrumento de placer del hombre, hay que añadirle la sufrida por la mujer lesbiana. Las lesbianas formaron a principios de 1977 un grupo independiente - aunque incluidas en el «Front d'Alliberament Homosexual del País Valencià»— denominado "Colectivo de Lesbianas del FAHPV", con discrepancias respecto al enfoque de sus luchas e incluso por su forma de entender la sexualidad. El Colectivo de lesbianas estuvo incluido hasta Febrero de 1978 en los denominados «Frentes Mixtos», incorporándose con posterioridad en el «Movimiento Feminista» (MF) como «Colectivos de Lesbianas Feministas» ${ }^{23}$.

\section{La lectura de La Voluntad de Saber en un grupo de militantes homosexuales}

La aparición de La Voluntad de Saber ${ }^{24}$, primer volumen de la Historia de la sexualidad de Michel Foucault, supuso un giro copernicano respecto a la concepción del poder, identificado previamente como una ley que sólo reprimía y prohibía. Su autor demostró que las relaciones de poder son mucho más complejas:

si el poder no fuera más que represivo, si no hiciera nunca otra cosa que decir no, ¿̨pensáis realmente que se le obedecería? Lo que hace que el poder agarre, que se le acepte, es simplemente que no pesa solamente como una fuerza que dice no, sino que de hecho la atraviesa, produce cosas, induce placer, forma saber, produce discursos; es preciso considerarlo como una red productiva

22 Este comunicado se considera uno de los primeros manifiestos públicos del «Col-lectiu de Lesbianes de Barcelona» (Marzo de 1978). Citado por Llamas, R., Vila, F. (1977) en Buxán, X. M. (ed.), (1997, 193).

23 "Colectivo de Lesbianas» (1978) en Enríquez, J. E. (compilador), (1978, 181 y ss).

${ }^{24}$ Foucault, M. (1976). La edición utilizada por este grupo de militantes homosexuales es la original. 
que atraviesa todo el cuerpo social más que como una instancia negativa que tiene como función reprimir ${ }^{25}$.

El discurso occidental contemporáneo sobre la emancipación de la sexualidad y el deseo se puso en tela de juicio cuando Foucault mostró que la presunta liberación estaba promovida por el poder e incluso denunció la complicidad objetiva entre el sexo y el sistema burgués. Es decir, una historia de la sexualidad que no estaba ordenada en función de un poder-represión o de un poder-censura, sino más bien fundamentado en la idea de un poder-incitación o de un poder-saber ${ }^{26}$.

Desde los presupuestos de La Voluntad de Saber constatamos la existencia de un grupo de militantes que adoptó una actitud crítica ante los planteamientos de la homosexualidad. Estas reflexiones fueron el resultado de una discusión de un colectivo de "izquierda revolucionaria», sin más identificación, cuya preocupación central era la transformación del mundo. No intentaron explicar ni justificar la homosexualidad, sino promover el debate para articular el incipiente combate homosexual en el conjunto de la actividad revolucionaria, descubriendo en la obra foucaultiana una serie de implicaciones ideológicas utilizadas en los discursos de la sexualidad:

la referencia a Foucault se hace necesaria, no como pretexto erudito ni como argumento de autoridad, sino porque creemos que sus últimos avances dan pie a un nuevo enriquecimiento del arsenal teórico de los revolucionarios forzándoles a replantearse muchas posiciones que parecían claramente establecidas; difícilmente se podrá de ahora en adelante seguir planteando el combate feminista, homosexual, etc. en los mismos términos en que se ha hecho hasta ahora. Será necesario volver más ampliamente sobre dichas posiciones, que inician lo que podríamos llamar la «crítica de la sexualidad $»^{27}$.

Como novedad, hicieron compatibles los textos foucaultianos con la filosofía marxista. Se opusieron a otros movimientos de homosexuales que tenían como objetivo la integración y la igualdad de los mismos, ayudados de una corte de psiquiatras, sociólogos, sexólogos, psicólogos, juristas y religiosos. Para estos últimos la liberación homosexual era posible sin llegar a cuestionarse el dispositivo

25 Foucault, M. (1978, 175-189, 182). Edición original, «Verité et pouvoir», (entrevista de A. Fontana en 1976) en Fontana, A., Pasquino, P. (1977, 3-28).

${ }^{26}$ Monclús, M. (1985, 95-105).

27 Llop, J. (1977, 6-7). 
sexual burgués, que pretendieron mejorar o hacerlo más igualitario, consistiendo su estrategia en provocar una serie de reajustes y readaptaciones del sistema para que éste llegase a comprender y acoger a los homosexuales. Este planteamiento lo identificaron con la formación francesa "Arcadie», organización que mantuvo contactos con el "Front d'Alliberament Gay de Catalunya ${ }^{28}$, considerada por los marxistas de carácter apolítico y reformista. Como muestra de sus tímidas luchas, «Arcadie» envió a las Cortes españolas un informe jurídico sobre el tema y notas de protesta a la prensa.

Este colectivo de «izquierda revolucionaria» pretendió forzar al resto de organizaciones de homosexuales a sobrepasar su estrechez de conceptos y miras. Para ello reivindicaron el derecho a hablar de ellos mismos, de su homosexualidad, sin necesitar el certificado de garantía de nadie. Se trataba de eliminar los límites del dispositivo sexual burgués, es decir, de asumir como objetivo no la liberación de una homosexualidad — en contraposición a una heterosexualidad — sino la propia superación teórica y práctica ${ }^{29}$. La sociedad burguesa había construido y normalizado el concepto de sexualidad, y dentro de ésta la formación de la homosexualidad que contó con la ayuda inestimable de la psiquiatría. Esta ciencia médica se encargó de clasificar, medir, analizar, añadir o quitar cromosomas, asignando mayor o menor dosis de hormonas masculinas o femeninas, e incluso exploró la infancia en busca de extrañas fijaciones o complejos, atribuidos a un carácter o a una personalidad común a todos los homosexuales ${ }^{30}$.

Estas reflexiones críticas a los movimientos de liberación sexual recaían sobre los que aceptaron, como punto de partida, un modelo represivo de homosexualidad. Su combate revolucionario apostaba por la destrucción del dispositivo de sexualidad, identificando el poder como una estrategia que englobaba mil tácticas y actuaba sobre mil relaciones de fuerzas. Junto a otros movimientos sociales como el feminista, el movimiento por la libertad del aborto y la contraconcepción, y el de los psiquiatras progresistas, intentaron romper el esquema hombre-mujer o el binomio masculinidad-feminidad. Esta superación sólo sería posible mediante una nueva práctica liberadora que reivindicase los conceptos de cuerpo y placer:

${ }^{28}$ El FAGC escribió a los Obispos, procuradores en Cortes, para manifestar su indignación a raíz de la publicación de la LPRS. Véase, Viladegut, P., Solís, D. (1977, 34-35).

${ }^{29}$ Llop, J. (1977, 5-18).

30 Sobre la desaparición de la amistad y la declaración de la homosexualidad como un problema socio-político-médico véase, Cancio, M. (1986, 77-80). 
"contra el dispositivo de sexualidad, el punto de apoyo del contraataque no debe ser el sexo-deseo, sino los cuerpos y los placeres» ${ }^{31}$.

En estas interpretaciones del «Foucault construido en España $»^{32}$ en los años 70 podemos constatar una mayor riqueza de la «caja de herramientas foucaultiana», es decir, en los grupos sociales que hicieron un uso político y reivindicativo de su obra, entre los cuales sobresalen los movimientos de liberación sexual.

\section{Conclusión: La homosexualidad y los partidos revolucionarios durante la transición}

El concepto de sexo, lejos de ser un dato neutro se interpretó como una construcción artificial que había sido definida de mil maneras. El colectivo de militantes homosexuales aludido había interpretado La Voluntad de Saber en clave marxista, sin estimar la postura generalizada del marxismo, en tanto que la relación entre los sexos fue un tema secundario en la teoría marxista, centrada en el antagonismo de clases. El ensayo El origen de la familia, la propiedad privada y el Estado se utilizó como base de explicaciones posteriores que desde el marxismo se dieron al conflicto de sexos. Friedric Engels, apoyado en la teoría evolucionista del antropólogo Lewis Morgan, identificó el origen de la Humanidad con un comunismo sexual donde no existía el tabú del incesto, para más tarde establecerse la monogamia a medida que el varón fue mostrando sus preferencias por una de sus múltiples esposas ${ }^{33}$. Posteriormente el marxismo y sus ideales de revolución antiburguesa condenaron la homosexualidad al identificarla como un vicio habitual de las clases en el poder, e incluso Engels la rechazó por ser antinatural ${ }^{34}$.

Más cercano en la historia, los llamados "países socialistas» nunca se cuestionaron la familia, la moral y el modelo sexual burgués. La homosexualidad seguía siendo reprimida y condenada públicamente como residuo decadente de la sociedad burguesa. Con el triunfo de la Revolución Rusa en 1917 se suprimieron, por primera vez en el siglo XX, las leyes antihomosexuales y se abolieron las instituciones que amenazaban a la sexualidad en general. Y el homosexual,

31 Foucault, M. (1977, 191).

32 Galván, V. (2010).

33 Puleo, A. (1993, 65-82).

${ }^{34}$ Engels, F. (1971). 
al menos legalmente, fue libre. No tardaron demasiado en imponerse unas leyes aún más duras que las que existían, como fueron las propuestas por Stalin en 1934. A partir de entonces se definió la homosexualidad como una tara de la burguesía, posibilitando que todos los países comunistas orientales y occidentales reprimiesen a los homosexuales, e incluso se negaron a utilizar el calificativo «homosexual» para evitar un debate en el partido.

En España el desmantelamiento paulatino de la Dictadura fue paralelo a la toma de conciencia de los movimientos de liberación gays y al desenvolvimiento de las luchas feministas. Si bien, estos colectivos suscitaron la alarma y el espanto no sólo de los sectores más reaccionarios y tradicionales del franquismo y nostálgicos del catolicismo, sino también de la izquierda y extrema izquierda. Las declaraciones siguientes sobre la homosexualidad demuestran su participación de la ideología de las clases dominantes y de la moral franco-católica, al igual que su escaso interés por el problema específico de la marginación.

En 1977 los periodistas Fernando Ruiz y Joaquín Romero realizaron un cuestionario a líderes de partidos marxistas españoles, donde incluían la pregunta ¿qué opinión te merece la homosexualidad? Estas son algunas de las respuestas condenatorias e insultantes de los dirigentes supuestamente revolucionarios: «En la sociedad actual, la homosexualidad no viene motivada por unos defectos físicos, sino ante todo por una degeneración de la vida. En este sentido, la homosexualidad ha de ser condenada». (Eladio García Castro, Partido del Trabajo de España, PTE) $)^{35}$. O esta otra afirmación:

Creo que, en cierta medida, se recurre a la homosexualidad por no ser capaz de afrontar otras responsabilidades y otras cuestiones. Por principio, no me opongo a que existan homosexuales, pero pienso que ni hay que estimularles ni hacer una liga para defenderlos.

(Diego Fábregas, Organización de Izquierda Comunista, OIC) ${ }^{36}$.Y la última: «La homosexualidad es una alteración de la sexualidad. No es una forma normal de entender las relaciones sexuales, no es un modo natural y puede verse en un tipo de deformación educativa, psicológica o física». (Manuel Guedán, Organiza-

35 Ruiz, F., Romero, J. (1977, 164). El libro recoge nueve entrevistas con líderes de partidos marxistas y sus respectivos programas; y también otros trece programas de partidos políticos cuya incidencia era relevante en algunas comunidades.

36 Ibídem, Pág. 93. 
ción Revolucionaria de Trabajadores, ORT) ${ }^{37}$. Estos partidos políticos, respecto a los problemas de la sexualidad, incidían más en la ideología y no en el individuo, considerando la homosexualidad como una consecuencia de la sociedad burguesa capitalista, que sólo podía existir en ese tipo de sociedad, por tanto presuponían que en la sociedad socialista no existirían homosexuales. Por otra parte, el arraigo histórico del machismo existente en nuestro país comporta una posible lectura política: los partidos de izquierda eran conscientes del impresionante tabú social que representaba la homosexualidad, por lo que hicieron todo lo posible por abstenerse o no reconocer oficialmente su postura ante la homosexualidad, ya que ésta podía restarles votos.

La mayoría de los partidos revolucionarios eludieron enfrentarse al marco de costumbres de la sociedad burguesa: sexualidad, relaciones interpersonales, erotismo, institución familiar, etc. Juan Goytisolo denunció el razonamiento de estos líderes marxistas-leninistas, que lamentaban la alienación de los obreros en las fábricas pero no las que sufrían las mujeres en sus propias casas:

Se puede ser antiesclavista, pero burgués. Se puede ser republicano y colonialista. Se puede ser obrero, pero machista. Se puede ser defensor de los derechos de la mujer, los negros y los obreros, y perseguir a los homosexuales. Pero no se puede pretender el nombre de revolucionario sin extraer el común denominador de todas las opresiones, a fin de denunciarlas y combatirlas. ${ }^{38}$

\section{Bibliografía}

BuXán, X. (1997). Conciencia de un singular deseo. Barcelona: Alertes.

Cancio, M. (1986). «Entrevista con Michel Foucault: El poder, el sadomasoquismo y el estado", Ábaco. Revista de cultura y ciencias sociales, n. ${ }^{\circ}$ 1, Pág. 77-80.

Carlavilla del Barrio, M. (1973). Sodomitas. Madrid: Editorial NOS.

Comité Pro-Presos de CNT. (1977), «La Copel: el detonante de los presos comunes», Bicicleta. Revista de Comunicaciones Libertarias, n. ${ }^{\circ}$ 1, Pág. 36-39.

Documento «Hacia la total liberación sexual» firmado por Helios en VV.AA. (1977). Mujeres Libres. Aproximación a Mujeres Libres, Barcelona: Memorial Democràtic, Pág. 231-233.

37 Ibidem, Pág. 108.

38 Goytisolo, J. (1978, 8-11,11). 
Engels, F. (1971). El origen de la familia, la propiedad privada y el Estado. Madrid: Fundamentos.

ENRíQuez, J. E. et al. (eds.), (1978). El homosexual ante la sociedad enferma. Barcelona: Tusquets.

Fluviá, A. (1977). «Los movimientos de liberación homosexual en el Estado español» en Weinberg, M., Williams, C. J. (eds.), (1977). Homosexuales masculinos. Sus problemas y adaptación. Barcelona: Fontanella, Pág. 485-501.

Fluviá, A. (1978). «El movimiento homosexual en el estado español» en EnríQuez, J. E. et al. (eds.), (1978). El homosexual ante la sociedad enferma. Barcelona: Tusquets, Pág. 149-167.

Fluviá, A. (1979). Aspectos juridico-legales de la homosexualidad. Barcelona: Instituto Lambda.

Folguera, P. (2007). «De la Transición política a la paridad» en Folguera, P. (ed.), (2007). El feminismo en España. Dos siglos de Historia. Madrid: Fundación Pablo Iglesias, Pág. 157-200.

Foucault, M. (1977). Historia de la Sexualidad I. La Voluntad de Saber. Méjico: Siglo XXI. (Traducción de Ulises Guiñazú). Edición original, Foucault, M. (1976). Histoire de la sexualité 1. La Volonté de Savoir. París: Gallimard.

Foucault, M. (1978). "Verdad y poder» en Foucault, M. (1978). Microfísica del poder. Madrid: La Piqueta, Pág. 175-189. (Traducción de J. Varela y F. ÁlvarezUría). Edición original, "Verité et pouvoir», (entrevista de A. Fontana en 1976) en Fontana, A., Pasquino, P. (1977). Michel Foucault. Microfisica del potere. Interventi politici, Pág. 3-28.

Foucault, M. (1977). «No al sexo rey», Triunfo, n. ${ }^{\circ}$ 752, 25 Junio, Pág. 46-51. Edición original, «Foucault: non au sexe roi» (Entrevista de B. Henry-Lèvi), Le Nouvel Observateur, n. ${ }^{\circ}$ 644, 12 Marzo, Pág. 92-103.

Foucault, M. (1990). «Los anormales» en Foucault, M. (1990). La vida de los hombres infames, Madrid: La Piqueta, Pág. 83-91. (Traducción de J. Varela y F. ÁlvarezUría). Edición original, "Les anormaux», Annuaire du Collège de France, (Resumen del Curso 1974-1975), Pág. 335-339.

Foucault, M. (1985). «El combate de la castidad» en Foucault, M. (1985). Saber y Verdad. Madrid: La Piqueta, Pág. 167-182. Edición original, Foucault, M. (1982) «Le combat de la chasteté», Communications, n. o 35, Mayo, Pág. 15-25.

Galván, V. (2010). De vagos y maleantes. Michel Foucault en España. Barcelona: Virus Editorial.

García PÉrez, A. (1976). La rebelión de los homosexuales. Madrid: Pecosa. 
García Valdés, A. (1981). Historia y presente de la homosexualidad. Análisis crítico de un fenómeno conflictivo. Barcelona: Akal.

Gómez-Beneyto, M. (1976). «La marginación del homosexual vista por un psicólogo-psiquiatra» en TEMAS MONOGRÁFICOS DE SEXOLOGÍA (1976), n. 1 : Aspectos médico-cientificos de la homosexualidad. Barcelona: Instituto Lambda.

Gómez-Beneyto, M. (1978). «Algunos aspectos médicos, psicológicos y jurídicos de la homosexualidad» en Torres GonzÁlez, F. (coord.), (1978): Los marginados en España. Madrid: Fundamentos, Pág. 141-154.

Goytisolo, J. (1978). «Remedios de la concupiscencia según Fray Tierno», El Viejo Topo, n. ${ }^{\circ}$ 16, Enero, 1978, Pág. 8-11.

Haro Ibars, E. (1978). «La homosexualidad, una herejía de nuestro tiempo», Triunfo, n. ${ }^{\circ}$ 82, 25 de Noviembre, Pág. 59.

Hegewicz, E. (1977). «Foucault: los avatares del poder», Diario de Barcelona, 20 de Mayo, Pág. 30.

Hocquenghem, G. (1974). Homosexualidad y sociedad represiva. Buenos Aires: Granica.

Llamas, R., VIla, F. (1998). «Spain: pasión for life. Una historia del movimiento de lesbianas y gays en el estado español» en BUXÁN, X. (1997). Conciencia de un singular deseo. Barcelona: Laertes, Pág. 189-224.

Lıop, J. (1977). «Reflexiones críticas sobre el combate sexual», Negaciones, n. ${ }^{4}$ 4, JulioSeptiembre, Pág. 5-18.

López Linage, J. (coord.), (1977). Grupos marginados y Peligrosidad social. Madrid: Campo Abierto Ediciones.

Mapelli, B., Grosso, M. (1978). «La cuestión homosexual. El problema legal«», El Viejo Topo, n. ${ }^{\circ} 23$, Agosto, 1978, Pág. 18-20.

Mesa Redonda (1977). «Homosexuales, una lucha marginal», Teoría y práctica. La lucha de clases analizada por sus protagonistas, n. ${ }^{\circ} 12$, Octubre, Pág. 78-87.

Monclús, A. (1985). «El problema del poder: ámbito y disolución», Leviatán, n. ${ }^{\circ} 19$, Primavera, Pág. 95-105.

Moreno Sardá, A. (2007). «La réplica de las mujeres al franquismo» en Folguera, P. (ed.), (2007), El feminismo en España. Dos siglos de Historia. Madrid: Fundación Pablo Iglesias, Pág. 123-156.

Morey, M. (1977). «El poder, perverso y polimorfo», Diario de Barcelona, 20 de Mayo, Pág. 30.

Morey, M. (1978). Sexo, Poder, Verdad. Conversaciones con Michel Foucault. Barcelona: Cuadernos Materiales. 
Morey, M. (1983). Lectura de Michel Foucault. Madrid: Taurus.

Nash, M. (1976). Mujeres libres: España 1936-1939. Barcelona: Tusquets.

Puleo, A. (1992). Dialéctica de la sexualidad. Género y sexo en la Filosofía Contemporánea, Madrid: Cátedra.

Puleo, A. (1993). «Dos escuelas de la sospecha: hombre y mujer en el materialismo histórico y el psicoanálisis» en PULEO, A. et al. (1993). La Filosofía, ¿es un arma cargada de futuro? Madrid: Publicaciones del Ministerio de Educación y Ciencia, Pág. 65-82.

Ruiz, F., Romero, J. (Edición a cargo de...), (1977). Los partidos marxistas. Sus dirigentes, sus programas. Barcelona: Anagrama.

Sabater y Tomás, A. (1962). Gamberros, homosexuales, vagos y maleantes. Barcelona: Hispano Europea.

Soriano, M. (1978). Homosexualidad y represión. Iniciación al estudio de la homofilia, Madrid: Zero.

Torres GonzÁlez, F. (coord.), (1978). Los marginados en España. Madrid: Fundamentos.

VIejo Topo, (1977). «Aspectos reivindicativos del FAGC y del FHAR», n. ${ }^{\text {8 }}$, Mayo, Pág. 36-37.

Viladegut, P., Solís, D. (1977). «Todos somos bisexuales» (Entrevista con el secretario general del FAGC), El Viejo Topo, n. ${ }^{o}$ 8, Mayo, 1977, Pág. 34-35.

Weinberg, M. S., Williams, C. J. et al. (eds.) (1977). Homosexuales masculinos. Sus problemas y adaptación. Barcelona: Fontanella.

Recibido: 29/02/2012

Aceptado: 12/06/2012 